\title{
Discursos da rua e o homem público na sociedade midiática
}

\author{
Saraí Schmidt \\ Carolina Rigo
}

\section{Urbanização desvairada}

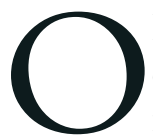

Brasil surge urbano, afirma Darcy Ribeiro (1995). Em um processo caótico, o espaço rural é transformado pela lógica industrial. O campo, anteriormente autônomo para os que ali viviam, passa a depender da cidade para sua subsistência quando se volta para o plantio da monocultura, em especial a partir do Brasil Império com o predomínio do café. Assim como a Abolição da forma que foi efetivada leva os negros para outra forma de exploração, agora nas periferias das cidades, a personagem Sergipano, de Jorge Amado ${ }^{1}$, na fase dos barões do cacau, é apenas um exemplo dentre tantos agregados, alugados e desafortunados que vieram a povoar os centros urbanos, aglomerando-se em favelas para buscar e lutar pela oportunidade de um modo de vida que oferecesse mais do que jaca e carne seca. Para Buarque de Holanda (1995: 172-173),

(...) podemos considerar dois movimentos simultâneos e convergentes através de toda a nossa evolução histórica: um tendente a dilatar a ação das comunidades urbanas e outro que restringe a influência dos centros rurais, transformados, ao cabo, em simples fontes abastecedoras, em colônias das cidades.

Sempre sedutoras e favorecendo as fantasias de uma vida melhor, as cidades crescem em número ao mesmo tempo em que se tornam complexos conjuntos humanos. De acordo com projeção estatística do $\mathrm{IBGE}^{2}$, divulgada em agosto de 2013, que considera como número base o último censo, realizado em 2010, 16 municípios 
brasileiros contam com mais de 1 milhão de habitantes. Em 1950 - utilizando os dados lançados por Darcy Ribeiro em O povo brasileiro - apenas São Paulo e Rio de Janeiro apresentavam tal contingente populacional; e em 1991, eram 11 cidades. A população urbana, que em 1991 correspondia a 75,47\% da população, passa em 2010 para $84,36 \%^{3}$, deixando no ambiente rural apenas 15,64\% dos habitantes brasileiros. Esse último dado representa um encolhimento da população rural de cerca de 6.200.000 pessoas, quando a população total do país cresceu, no mesmo período, 43.838.340.

Esses agrupamentos vão se formando na sua maioria desordenadamente e de maneira não satisfatória. No caso brasileiro, particularmente para a parte da população que se concentra na periferia e para as que dependem de serviços públicos. Pessoas de diferentes culturas - muitas das quais separadas do ambiente doméstico porque deixaram suas famílias para trás - passam a viver em bairros, vilas ou guetos e a compartilhar os espaços comuns. Postos nessa nova situação, os indivíduos são requeridos a ajustar-se ao ambiente impessoal da cidade e entre os desconhecidos que transitam e se entrecruzam nas calçadas. Não olhar e não dirigir a palavra tornam-se atos de respeito. Se não há contato, não há enfrentamento ou provocação. É possível, assim, seguir o caminho sem olhar para trás.

As cidades são vistas como os locais para trabalhar, morar e viver porque é ali que há maiores vagas de trabalho e "opções de escolha" para mentes e corações consumidores. Porque é ali que o ritmo serial incessante oferece em prontidão as novidades obsoletas de amanhã. $\mathrm{O}$ ritmo serial e incessante das cidades parece depreciar atos como o devaneio e a desatenção, pelo predomínio da necessidade de respostas e opiniões. A magia da vida cotidiana vai se esvaindo por entre os bueiros da burocracia e da produtividade. Parece haver pouco tempo nas urbes ou poucos motivos para perder-se por suas ruas, onde teimamos em caminhar pelos trajetos conhecidos.

Bosi (2008) destaca que passamos por um período de exacerbada produção e consumo de signos, fomentado pela cultura de massa e seus meios de comunicação. Embora o autor apresente a pluralidade cultural que constitui as cidades, com as culturas popular e erudita - estas oferecendo formas de resistência para a cadência da cultura de massa -, ele destaca a relevância de pensar acerca desse tempo singular dos centros urbanos: “(...) é preciso que o espírito do consumidor conheça outros ritmos que não o da indústria de signos. Se isso não ocorrer, teremos, no limite do sistema, o 'homem unidimensional' de Marcuse, como todos os riscos políticos que traz a massificação", (Bosi, 2008: 10).

Partindo do pressuposto de que é nas cidades que convivemos uns com os outros e de ser pelas ruas que invariavelmente nos movimentamos, é interessante pensar a relação do indivíduo com os espaços exteriores urbanos. Esses lugares de subcidadania - porque de muitos deveres e parcos direitos -, nos termos de DaMatta 
(1997). Muitos “coletivos” independentes surgiram nos últimos anos. Várias de suas propostas referem-se à ocupação de espaços públicos inutilizados, esquecidos pelo poder público ou que vieram a sofrer interferências por decisões políticas. Artistas ganham visibilidade nas ruas por meio das Leis de Incentivo, de editais do Ministério e das Secretarias de Cultura e dos, a cada dia mais ativos e numerosos, crowdfundings ${ }^{4}$. Outros artistas se apropriam de muros e fachadas sem pedir licença ou esperar em troca algum retorno financeiro.

O espaço urbano está sofrendo, cotidianamente, intervenções que fogem da ordem do sempre presente desenvolvimento imobiliário e outras obras estruturais. Sendo assim, é possível enxergar, nos tempos atuais, transformações na relação do indivíduo brasileiro com o que é da ordem do comum ou permanece a conduta do homem cordial, que tende priorizar vontades particularistas, privatizando o espaço público? Ações propostas por coletivos e artistas são o início de práticas disruptivas de cidadania na cultura brasileira ou trata-se do fortalecimento do nosso caráter? Essas são as questões norteadoras que o artigo buscará discutir.

\section{Coisas que as ruas falam}

Inicialmente cabe pensar sobre o processo de formação da sociedade brasileira, sentidos e sentimentos acerca dos múltiplos significados para rua, articulando-os às possíveis condutas do homem público. A rua torna-se um lugar que permite diferentes significados no tempo no qual vivemos. Podendo ser compreendida tanto o espaço do anonimato como o espaço do espetáculo.

A rua é o lugar do inesperado. Mesmo no bairro onde cada casa e cada fruteira são conhecidas, podemos nos surpreender com um transeunte de comportamento espalhafatoso, com a senhora que hoje não está à janela, com um canto obscuro que ainda não havíamos visto. $\mathrm{O}$ acaso da rua pode envolver "confusão, competição e desordem" (DaMatta, 1986: 27), em oposição à organização controlada e ao aconchego do lar. Na rua podemos ser anônimos, apenas mais um, e, portanto, ninguém, a transitar em fluxo contínuo de um ponto a outro. Indivíduos com rosto, mas sem identidade porque desconhecidos. Reconhecimento, segurança, respeito e afeto encontrados na casa não estão presentes nesse universo onde mazelas de toda sorte podem ocorrer. A violência urbana é apresentada diariamente pelos noticiários, programas de auditório e folhetins. Cabe lembrar que em 2002, filmes que retratavam a violência pelas ruas brasileiras (Cidade de Deus; Madame Satã; Ônibus 174; O invasor) contribuíram para que o cinema nacional retomasse seu vigor fazendo um contraponto à avalanche de estrangeirismos nas salas de exibição ${ }^{5}$. Com a exposição da violência urbana das ruas da cidade maravilhosa a telona mobilizou um contingente significativo da bilheteria nacional e evidenciou os movimentos daqueles que vivem fora do centro. 
A impessoalidade da rua brasileira interfere diretamente no sentido de cidadania, porque ali é preciso abrir mão das redes de contatos (DaMatta, 1986). Se no lar o comportamento é de supercidadãos, porque é onde são criadas normas próprias ou é onde são encontradas brechas para subvertê-las com base em relações pessoais, na rua, o comportamento é de um subcidadão: aparentemente obediente ao que é oferecido, e à deriva das surpresas decorrentes das individualidades e individualismos de tantos desconhecidos. Uns iguais aos outros na condição do anonimato e da inépcia. A rua, entretanto, vem se mostrando um espaço nobre e interessante para movimentos e mobilizações diversificados. Os governos começam a temer o empoderamento das ruas quando ela torna-se um palco, um espaço para ampliar diferentes vozes. A rua torna-se um local de encontro e desencontro colocando em xeque a noção de público e privado.

A oposição público/privado, ou cidade/família - para nos aproximarmos dos termos de Buarque de Holanda -, deveria ser, na perspectiva desse autor, bastante marcada, porque existe uma incompatibilidade fundamental entre esses dois princípios: de um lado a noção abstrata e impessoal da cidade; de outro, a realidade concreta e tangível da família. Sendo assim, é apenas por meio da transgressão do que é do âmbito familiar que se forma o cidadão responsável (Buarque de Holanda, 1995: 141). Para o homem cordial, contudo, a rua é um espaço impossível nesses termos, uma vez que traços constitutivos de seu caráter - como a aparência da cordialidade, a polidez e a hospitalidade - somente escondem características herdadas de uma tradição rural e patriarcal que acaba por preservar inalteradas suas sensibilidades e emoções. Buarque de Holanda (1995: 146-147) afirma ainda que

(...) seria engano supor que essas virtudes possam significar "boas maneiras", civilidade. São antes de tudo expressões legítimas de um fundo emotivo extremamente rico e transbordante. Na civilidade há qualquer coisa de coercitivo - ela pode exprimir-se em mandamentos e sentenças.

A experiência do coletivo RUA (Rastro Urbano de Amor) pode contribuir para uma reflexão sobre a desafiadora e complexa relação do binômio público/privado quando tal manifestação agencia o embaçamento dessas fronteiras. Fundado em abril de 2012, em Porto Alegre, o coletivo tem como proposta fomentar intervenções em espaços públicos para tirá-los do anonimato ou ressignificá-los. Um dos seus eventos propostos ocorreu no Largo dos Açorianos, com o intuito de promover a Ponte de Pedra (cartão postal da capital gaúcha, mas rotineiramente deserta de habitantes) e o seu entorno próximo ao centro histórico. O espaço foi palco de atrações artísticas e reuniu muitas pessoas. Nas palavras de uma das fundadoras do grupo, os lugares escolhidos para as ações "podem ser locais de troca afetiva e ganhar significado através de algo pacífico e lúdico" 
Movido por um viés poético e romântico, o RUA vai sugerindo que a rua se assemelhe ao espaço da casa: seguro e afetuoso. Dessa forma, é reafirmado o imaginário ideal que envolve a família como espaço moral superior ao domínio público. Por outro lado, ele preserva a impessoalidade característica do ambiente exterior quando ali não interessa quem é quem. O acesso, as atrações e a possibilidade de se apresentar artisticamente estão disponíveis para "qualquer um". Muitos dos participantes conhecem apenas outros indivíduos na mesma condição: com o interesse comum de frequentar a região.

Embora tenha pouca importância a personalidade dos demais envolvidos no evento e haja presença de grupos que não se conhecem, parece que a motivação em participar está mais ligada à "compulsão de estar perto dos outros" do que de "viver com os outros" (Sennett, 1988: 324), já que o comportamento preponderante é o da observação entre os desconhecidos e não o de realização conjunta de ações específicas. Nesse sentido, vale destacar o pensamento de Buarque de Holanda (1995) acerca de nossas heranças ibéricas no que tange à atividade utilitária e à harmonia de interesses e ao homem cordial que não sabe viver sozinho.

Para o autor, os vínculos entre espanhóis e portugueses privilegiam a associação entre os homens nos círculos da ordem doméstica (família e amigos). Vínculos, portanto, formados com base em sentimento em vez de serem formados a partir de uma atividade utilitária racional que surge do interesse de criar algo exterior ao indivíduo e distinto dele - maior que ele. Com efeito, nas ocasiões em que não há necessidade de construção mecânica conjunta, solidifica-se um ideal de que a vida boa é a vida ociosa: sem esforços e sem preocupações. Ou seja, a atividade produtora para as nações ibéricas "é, em si, menos valiosa que a contemplação e o amor", (Buarque de Holanda, 1995: 38).

O RUA convida anônimos para participarem de um ato cujo propósito reside em afeto e no convívio pacífico, polido e contemplativo dos indivíduos. O RUA convoca prioritariamente o homem cordial. Esse indivíduo que precisa estar perto dos outros e cuja

(...) vida em sociedade é, de certo modo, uma verdadeira libertação do pavor que ele sente em viver consigo mesmo, em apoiar-se sobre si próprio em todas as circunstâncias da existência. Sua maneira de expansão para com os outros reduz o indivíduo, cada vez mais, à parcela social, periférica, que no brasileiro tende a ser a que mais importa. Ela é antes um viver nos outros (Buarque de Holanda, 1995: 147).

Se, de um lado, aprendemos com os ibéricos a privilegiar laços na ordem do familiar; de outro, é possível notar que a cultura da personalidade - constitutiva dessas nações - não se adaptou tão bem aos trópicos. Para espanhóis e portugueses 
o valor maior do indivíduo está na sua capacidade de não depender de outros, de bastar-se, em que "cada qual é filho de si mesmo, de seu esforço próprio, de suas virtudes", (Buarque de Holanda, 1995: 32). Diferente, portanto, do comportamento do homem cordial, que mantém relações próximas, sobretudo, com pessoas que podem ser relevantes para o exercício de privilégios, rompendo regras coletivas. Esse predomínio/tirania da individualidade, contudo, tampouco favorece ações solidárias coesas entre desconhecidos, ensina o autor.

A espontaneidade harmônica nessa reunião sem obrigações, hierarquia ou qualquer tipo de rito, não favorece, portanto, o vínculo entre os indivíduos para além dos círculos já formados de amizade. O formato dado à ação e o discurso do RUA corrobora a estrutura do caráter do povo brasileiro. Um novo olhar sobre a cidade é lançado para que cada um dos indivíduos, separadamente ou nos seus grupos sociais próximos, talvez, ponha-se a pensar a cidade onde vive. Sem respostas ou soluções prontas, mas também sem laços firmes de solidariedade anônima.

A partir do exposto até o momento vale abordar as duas lógicas operantes na cidadania brasileira na visão de DaMatta $(1986 ; 1997)$. Uma delas é a que atua no âmbito do discurso e da burocracia, proclamando a ordem universal: da imparcialidade e da igualdade de todos os membros que constituem a nação. O discurso recorrente é de que os indivíduos devem obedecer às leis e normas postas. Estas, contudo, criadas, não com a participação dos cidadãos, mas pelo próprio Estado, desde o período colonial, como instrumentos de "ordem e progresso". Habituamo-nos, assim, a uma forma de organização dada, cujo processo não fomentou a autonomia nem o aprendizado de negociação dos indivíduos. Nossa tendência é aceitar o que nos apresentam com um sorriso no rosto para, sem receio, descumprir às escondidas com o que não concordamos.

Manoel, um vaqueiro do sertão de Lampião e Maria Bonita, não se conforma com a regra criada pelo coronel Moraes, que se recusa a pagar ao vaqueiro o saldo por conduzir sua boiada, já que algumas das vacas morreram no inóspito trajeto. Manoel mata o coronel e a partir desse momento começa sua peregrinação pelo sertão, onde a personagem, primeiro se sujeita ao líder beato Sebastião e depois da morte deste, passa a seguir, ainda que incrédulo, as ordens do cangaceiro Corisco. Em um lampejo de vontade e de revolta com leis dadas que não lhe favoreciam, Manoel comete um ato violento que o atormenta posteriormente. Na busca de redenção se submete a outras verdades que tampouco parecem lhe ser favoráveis.

O sertanejo protagonista de Deus e o diabo na terra do sol (1964), de Glauber Rocha, apresenta diversas vezes, durante a narrativa fílmica, a tensão presente na sociedade brasileira entre obediência e autonomia. Um espaço que não sabemos direito como preencher, que nunca aprendemos como fazer porque em nosso processo histórico não houve apoio aos atos espontâneos ou aos que se contrapunham ao que já estava tradicionalmente estabelecido. Ou, ainda, porque, como aponta 
DaMatta (1997: 81), somos uma nação onde muitos códigos de comportamento - complementares - operam simultaneamente: "o que um nega, outro pode facultar". Seria essa dificuldade também um legado da ambivalência existente nos povos ibéricos, cuja única reação possível ao valor supremo da individualidade é a obediência desmedida? Nas palavras de Buarque de Holanda (1995: 39), em resposta

(...) à autarquia do indivíduo, à exaltação extrema da personalidade, paixão fundamental e que não tolera compromissos, só pode haver uma alternativa: a renúncia a essa mesma personalidade em vista de um bem maior. (...) não existe, a seu ver, outra sorte de disciplina perfeitamente concebível, além da que se funde na excessiva centralização do poder e na obediência.

Passemos, assim, para a segunda lógica da cidadania. Não mais na ordem do discurso, mas na da prática e que se dá a partir do espaço da "casa". Os princípios igualitários desaparecem para dar lugar aos privilégios procedentes das relações afetivas que o sujeito, agora dotado de identidade, estabeleceu ao longo de sua vida social. Surge, portanto, uma cidadania que se realiza no âmbito privado, em que os interesses particulares de alguns - dos que herdaram ou formaram laços convenientes - predominam sobre a ordem coletiva. Normas são quebradas para emergir o "jeitinho brasileiro" que revela o predomínio do "emotivo sobre o racional" na nossa cultura (Buarque de Holanda, 1995: 182). É nesse sentido que

(...) a obediência às leis configura na sociedade brasileira uma situação de pleno anonimato e grande inferioridade. Normalmente é um sinal de ausência de relações e são as relações que permitem revestir uma pessoa de humanidade, resgatando-a de sua condição de universalidade que é dada nos papeis de cidadão e de individuo (DaMatta, 1997: 74-75).

Essa segunda lógica da cidadania, Manoel não possui. Ele não herdou nome, nem propriedade. Seus esforços individuais não geraram uma rede de contatos que pudesse ser acionada para dar conta do que regras deixavam escapar. A ele the cabe permanecer na vala comum, na do "para todos", na do "mais um". O anonimato é um problema para a personagem, assim como é para muitos brasileiros. E certamente há motivos concretos para a qualidade de "qualquer um" ser encarada como problema quando no processo histórico brasileiro,

(...) só excepcionalmente tivemos um sistema administrativo e um corpo de funcionários puramente dedicados a interesses objetivos e fundados nesses interesses. Ao contrário, é possível acompanhar, ao longo de nossa história, o 
predomínio constante das vontades particulares que encontram seu ambiente próprio em círculos fechados e pouco acessíveis a uma ordenação impessoal. Dentre esses círculos, foi sem dúvida o da família aquele que se exprimiu com mais força e desenvoltura em nossa sociedade (Buarque de Holanda, 1995: 146).

Mas, olhemos para outros dois movimentos da capital gaúcha. O Defesa Pública da Alegria é uma organização autônoma surgida em Porto Alegre, também em 2012. O grupo proclama a cidade como um espaço de convívio igualitário e, assim, defende espaços públicos contra privatizações e outras medidas cerceatórias, crescentes na capital gaúcha. Suas estratégias se baseiam em ações efêmeras, abertas, pacíficas e artísticas. Desde a fundação, foram muitas as ações arranjadas pelo Defesa Pública da Alegria. Dentre elas, o grupo convocou a população para um encontro em que reivindicava diálogo entre governo e porto-alegrenses acerca do projeto de revitalização do Cais Mauá. O fato é que a prefeitura acordou concessão do cais pelo período de 25 anos para uma empresa privada. O projeto prevê - respeitando os setores declarados protegidos pelos Patrimônios Históricos Nacional e Municipal - a construção de shopping center, centro de convenção, hotel e estacionamento. Em um manifesto escrito pelo próprio coletivo, afirmam querer "um espaço para as diferentes culturas da cidade se encontrarem, onde o consumo não seja obrigatório". O evento ocorreu durante a tarde e a noite de um sábado e contou com apresentações de músicos e outras atividades artísticas. O Cais Mauá era tradicionalmente mantido aberto para circulação da população e abrigava, desde 2004, em alguns de seus armazéns, parte da Bienal do Mercosul.

Com abordagem semelhante ao movimento anterior e com o slogan "Porto Alegre para as pessoas", o evento Largo Vivo promove manifestações em espaços que vêm se descaracterizando. O lugar mais relevante onde acontecem os encontros é no Largo Glênio Peres, em frente ao Mercado Público de Porto Alegre. Todos os dias ocorriam ali apresentações populares, mas mediante acordo público-privado, esse lugar passou a ser um estacionamento, coibindo as performances. Conforme um dos participantes do Largo Vivo, "o que vemos aqui no Largo é um confronto direto de políticas públicas, onde a sociedade mostra querer uma coisa, mas a prefeitura outra"'. Por meio de atrações circenses, teatro, música, cartazes, stencil, entre outras atividades, o Largo Vivo enche "de vida a área que seria ocupada pelos carros", lê-se na divulgação de um dos eventos.

Em oposição à subcidadania em DaMatta e ao homem cordial em Buarque de Holanda, esses movimentos reclamam - para além das relações pessoais - um espaço que também lhes pertence, questionando a forma que a cidade está sendo conduzida por sua administração pública. A posição racionalizada da intenção, ou seja, do propósito da existência desses atos político-culturais - desestabilizadores da 
imagem do homem incapaz da impessoalidade e igualdade e submisso aos poderes institucionalizados -, confronta-se com o formato lúdico e pouco rígido dado aos eventos. Pessoas são convocadas a participar, mas sem deveres ou regras de conduta. Arte, alegria e brincadeira coabitam com o discurso reivindicatório dos coletivos. A atmosfera familiar marca o distanciamento dos formatos tradicionais de manifestações políticas e das convenções sociais. Novamente, portanto, o quadro é complexo porque os vínculos para a formação de um grupo coeso e durável mostram-se um tanto fragilizados.

Outra vez Buarque de Holanda pode ajudar a pensar sobre essa forma de agir política e coletivamente quando o autor analisa a relação que o brasileiro estabelece com os cultos religiosos. A intimidade que o povo trata dos santos - que descem para sambar com toda a gente, que são chamados em nomes no diminutivo -, a falta de rigor dos encontros que dispensam "no fiel todo esforço, toda diligência, toda tirania sobre si mesmo" (1995: 150). Nosso horror às distâncias e aos padrões de convívio humano que, mesmo em situações onde a concorrência deve ser preponderante - a das trocas comerciais, por exemplo - são orientadas pela força da emoção. A forma de tratamento que pouco apela para a razão, mas, ao contrário, apela, sobretudo, para um tratamento próximo e amistoso para com aqueles que podem vir a ser ou são de interesse em uma causa privada.

\section{Considerações finais}

Mas, afinal, no que consistiriam organizações sólidas no mundo de hoje? É possível pensar em ações perenes e coletivas que não sejam impostas, mas espontâneas, nesses aglomerados humanos tão plurais que são as grandes cidades? $\mathrm{Ou}$ faz sentido aceitar atos efêmeros que propõem relação com o que é da ordem do comum, próximos à ideia do que Hakim Bey (2011) denomina "levante". Para esse autor, "levantes" consistem em atuações temporárias que promovem o convívio com indivíduos desconhecidos e onde os códigos de conduta estão mais ou menos abertos para serem preenchidos conforme a negociação entre os participantes. A existência pontual dos levantes coibiria a formação das habituais comunidades que privilegiam a criação de uma personalidade coletiva, onde o indivíduo passa a reconhecer-se, a identificar-se. A ideia de levantes, portanto, recuperaria a "essência da urbanidade, isto é, que os homens podem agir juntos, sem a compulsão de serem os mesmos", (Sennett, 1988: 314).

A negatividade de tais ajuntamentos residiria na sua força. Por sua efemeridade e sua flexibilidade - facilitadoras da individualidade, da mudança, assim como da participação de indivíduos cada vez mais ocupados em tempos céleres - fica opaco o caráter da luta, do conflito de forças, da necessidade da entrega contínua para a busca de solução perdurável, de uma finalidade que está situada exterior 
ao indivíduo e que implica certa submissão dele ao objetivo. As características do jogo político se diluem na alegria do encontro familiar, mantendo, assim, nossa qualidade de "povo mais brando e mais comportado do mundo", (Buarque de Holanda, 1995: 177). Certa violência presente na rua e imperativa para a transformação, como indica o cinema engajado de Glauber Rocha, não se faz presente. O "caos" passa a ser amainado.

Movimentos sociais de categorias profissionais ou grupos "minoritários" não são novidade na história das nações em geral, nem da brasileira em particular. A cidade e suas ruas, contudo, como o cerne das preocupações e de discussão vem ganhando destaque nos últimos anos. Há novos olhares sendo lançados para esses espaços compartilhados. Parece haver crescente conscientização acerca da importância da rua para o bem-estar privado. É neste sentido que propomos repensar ou ampliar a concepção de público e privado quando pensamos nos movimentos que ocupam as ruas. Talvez possamos pensar a partir das palavras de Ortega a possibilidade de problematizar a "tirania da intimidade" do nosso tempo:

Nosso apego exacerbado à interioridade, à “tirania da intimidade”, não permite o cultivo de uma distância necessária para a amizade, já que o espaço para a amizade é o espaço entre os indivíduos, do mundo compartilhado - espaço da liberdade e do risco -, das ruas, das praças, dos passeios, dos teatros, dos cafés e não dos nossos condomínios fechados e dos nossos shoppings centers, meras próteses que prolongam a segurança do lar (Ortega, 2003: 162).

Os eventos citados - e tantas outras iniciativas não mencionadas - representam um microcosmos no ambiente da cidade, marcando um tempo próprio e com possíveis efeitos um tanto ambivalentes. Ali, a temporalidade não está ligada à produtividade, embora haja um propósito previamente explicitado. A atmosfera familiar carente de deveres colabora para retirar da invisibilidade o indivíduo que se dispõe a sair de sua casa para ser testemunha do movimento. O ócio e o imprevisto, que distinguem os encontros, podem se mostrar relevantes para a construção e reconstrução de convenções e de máscaras a serem usadas por indivíduos que precisam aprender a arte da negociação com o outro, em um espaço comum vivido. Mas esse mesmo tempo mágico - que não exige esforços pessoais de expressão e participação ativa - não contribui para a formação do sentimento do coletivo e tampouco favorece uma posição efetiva democrática quando ignora as estruturas formais políticas, reiterando a disposição do brasileiro para a solução individual. Essa é a encruzilhada da política contemporânea, onde a aglomeração parece ter em si mesma o seu objetivo e sua razão. Dessa forma, vale destacar o pensamento de Sennett (1988: 43) acerca da experiência pública a partir do século XIX: 
O comportamento público era um problema de observação e de participação passiva, um certo tipo de voyeurismo. (...) A pessoa está aberta para tudo e nada rejeita a priori de sua esfera de ação, contanto que não tenha de se tornar um participante ou envolver-se numa cena. Esse muro invisível de silêncio, enquanto um direito, significava que o conhecimento, em público, era questão de observação - das cenas, dos outros homens, dos locais. O conhecimento não seria mais produzido pelo trato social.

Possivelmente as reivindicações não sejam atendidas com as manifestações. Elas acabam sendo mais um meio de chamar atenção, de conseguir visibilidade e quórum ao trabalho continuado dos coletivos que não se dissolvem como os atos abertos e que consideram as estruturas formais do poder público. O comportamento voltado para o coletivo se encontra ainda frouxo, ainda opaco, ainda confuso, mas parece haver a insipiência de algo, e é preciso deixar emergir, contrariando nosso processo histórico de abafar os atos espontâneos e contrariando também a atmosfera atual de produção, onde as finalidades precisam estar sempre muito claras. "Deixar ser" talvez seja uma boa forma de experienciar outras maneiras de interação social na cidade, compreendendo-a na concepção na qual aposta Sennett (1988: 414), como:

(...) o fórum no qual se torna significativo unir-se a outras pessoas sem a compulsão de conhecê-las enquanto pessoas. Não creio que esse sonho seja inútil; a cidade surgiu como foco para vida social ativa, para o conflito e o jogo de interesses, para a experiência das possibilidades humanas, durante a maior parte da história do homem civilizado. Mas hoje em dia essa possibilidade civilizada está adormecida.

Neste momento de tantas mudanças, quando temos decretada a morte do "sujeito autônomo", quando as promessas do Iluminismo estão sendo revistas, quando já não acreditamos num caminho único através do qual atravessaremos uma ponte em direção à "libertação" de todos, quando falamos em continuidades e descontinuidades e quando não vemos mais a história como linear e orientada para o progresso, talvez seja possível buscar pistas, alguns fragmentos que nos ajudem a revisar algumas certezas compreendendo que o caos já não parece um mau lugar para reflexão. E é neste contexto que Skliar (1999: 16) nos lembra que "esta é uma época de guerras virtuais e pobrezas reais, onde o discurso sobre os outros, sobre a alteridade, adquire novos significados e perspectivas políticas".

Talvez possamos ponderar a produtividade imposta pela nova ordem global, que classifica os povos ou as pessoas, determinando o espaço que cada um deve ocupar. É este o mundo das soluções para um mundo moderno, onde milhões de pessoas se desfazem em matanças étnicas, morrem por falta de água potável, se 
destroem diante da desintegração do emprego, porém se reafirmam a partir de novas identidades e se nutrem de novos movimentos sociais. Neste sentido, Bauman (1999: 95) aponta que "a globalização atingiu agora um ponto em que não há volta. Todos nós dependemos uns dos outros, e a única escolha que temos é entre garantir mutuamente a vulnerabilidade e garantir mutuamente a nossa segurança comum". Talvez esta seja uma encruzilhada nesse tempo de descompasso. Ou seja, refletir sobre a produtividade do processo de globalização na relação com os discursos da rua e o homem público na sociedade midiática.

Saraí Schmidt Professora da Universidade Feevale saraichmidt@feevale.br

Carolina Rigo Mestre pela Universidade Feevale carolahlah@gmail.com

Recebido em agosto de 2015.

Aceito em fevereiro de 2016.

\section{Notas}

1. AMADO, Jorge. Cacau. In: Obras Ilustradas de Jorge Amado. São Paulo: Livraria Martins Editora, 1970. p. 117-222.

2. Dados disponíveis em: < http://exame.abril.com.br/brasil/noticias/as-300-cidadesmais-populosas-do-brasil-em-2013 > . Acesso em: 03 de janeiro de 2014.

3. Dados disponíveis em <http://www1.folha.uol.com.br/cotidiano/908759urbanizacao-atinge-a-maior-taxa-da-historia-mostra-censo.shtml> . Acesso em 03 de janeiro de 2014.

4. Crowdfunding refere-se a uma forma de financiamento coletivo. Acontece prioritariamente pela contribuição de pessoas físicas.

5. Pedro Butcher escreve sobre esse fenômeno no texto "Cinema brasileiro hoje", publicado pela Publifolha, São Paulo: 2005.

6. Excerto extraído de matéria jornalística em Zero Hora, de 07/11/2013. Disponível em: < http://zerohora.clicrbs.com.br/rs/geral/noticia/2013/11/coletivo-urbanopromove-evento-no-largo-dos-acorianos-em-porto-alegre-4325897.html > . Acesso em 6 de janeiro de 2014.

7. Excerto extraído de matéria jornalística em Sul 21, de 19/11/2011. Disponível em: < http://www.sul21.com.br/jornal/pedindo-uma-porto-alegre-para-as-pessoasmanifestantes-criam-o- $\%$ E2\%80\%9Clargo-vivo\%E2\%80\%9D/>. Acesso em 6 de janeiro de 2013. 


\section{Referências}

BAUMAN, Zygmunt. Globalização: as consequências humanas. Trad. Marcus Penchel. Rio de Janeiro: Jorge Zahar, 1999.

BEY, Hakim. TAZ: zona autônoma temporária. $3^{\mathrm{a}}$ ed. São Paulo: Conrad Editora do Brasil, 2011. BOSI, Alfredo. Plural, mas não caótico. In: situações. São Paulo: Editora Ática, 2008. p. 7- $\overline{15 .}$ . (Org.). Cultura Brasileira: temas e

BUARQUE DE HOLANDA, Sérgio. Raízes do Brasil. São Paulo: Companhia das Letras, 1995. DAMATTA, Roberto. A casa, a rua e o trabalho. In: Rio de Janeiro: Rocco, 1986. p. 21-34.

Cidadania. In: Brasil. 5a ed. Rio de Janeiro: Rocco, 1997. p. 59-86.

ORTEGA, Francisco. Para uma política da amizade: Arendt, Derrida, Foucault. Rio de Janeiro: Relume Dumará, 2000.

RIBEIRO, Darcy. A urbanização caótica. In: . O povo brasileiro: a formação e o sentido do Brasil. São Paulo: Companhia das Letras, 1995. p. 193-207.

SENNETT, Richard. O declínio do homem público: as tiranias da intimidade. São Paulo: Companhia das Letras, 1998.

SKLIAR, Carlos. A invenção e a exclusão da alteridade "deficiente" a partir dos significados da normalidade. Educação \& Realidade, Porto Alegre, v. 24, n. 2, p. 15-33, jul./dez. 1999.

\section{Filmografia}

AÏNOUZ, Karim. Madame Satã. Cor. Brasil e França. 2002. 105min.

BRANT, Beto. O invasor. Cor. Brasil. 2002. 97min.

MEIRELLES, Fernando. Cidade de Deus. Cor. Brasil. 2002. 130min.

PADILHA, José. Ônibus 174. Cor. Brasil. 2002. 150min.

ROCHA, Glauber. Deus e o diabo na terra do sol. P\&B. Brasil. 1964. 125min. 


\title{
Resumo
}

O artigo discute a possível emergência de práticas disruptivas de cidadania no Brasil ou o fortalecimento do caráter do homem cordial, articulando a forma que operam alguns movimentos sociais independentes atuais, que problematizam a relação administração pública, indivíduo e cidade, com o processo histórico de formação do espaço público no Brasil na sociedade midiática. Para tanto, foram utilizados os conceitos de cidadania brasileira em DaMatta (1986;1997), o de homem cordial em Buarque de Holanda (1995) e a proposta de homem público de Sennett (1998). O artigo evidencia a ambivalência desses movimentos que embaralham público e privado e que, mesmo situados no modus operandi da produtividade, apresentam possíveis brechas onde novas formas de convívio social podem emergir na sociedade midiática na qual estamos inseridos.

\section{Palavras-chave}

Espaço público. Mídia. Movimentos sociais independentes.

\begin{abstract}
Speeches from the streets and the public man in media society

The essay discusses the possible appearance of disruptive practices of citizenship in Brazil or the strengthening of brazilians friendly character. The analysis articulates the way that independent social movements works nowadays with the history of public space development in Brazil. These social movements question the relation amongst public administration, individual and city. For this purpose, it was used, mainly, the concepts of brazilian citizenship in DaMatta (1986, 1997), the "friendly man" in Buarque de Holanda (1995), and the proposition of public man in Sennett (1998). The article highlights ambivalences of these movements that blend public and private spaces and that even located at the modus operandi of productiveness, show possible interstices where a new way of acting in public can lead to new forms of social interaction in the media society which we live.
\end{abstract}

\section{Keywords}

Public space. Media. Independent social movements. 